\title{
El acceso a la justicia como condición para una reforma judicial en serio
}

\author{
JAVIER LA ROSA CALLE*
}

\author{
SUMARIO: I. HACIA UNA (NUEVA) NOCIÓN DE ACCESO A LA JUSTICIA.- \\ II. BARRERAS DE ACCESO A LA JUSTICIA: ¿DE QUÉ ESTAMOS \\ HABLANDO?- 1. BARRERAS INSTITUCIONALES. 2. BARRERAS SOCIALES. \\ 3. BARRERAS ECONÓMICAS. III. HACIA UN SISTEMA DE JUSTICIA INCLUSIVO.
}

\section{A MANERA DE PRESENTACIÓN}

En la última década, diversos esfuerzos por promover reformas judiciales en nuestro país se han frustrado, entre otras razones, por la ausencia de cambios estructurales que beneficien a la población rural y urbana marginal, tradicionalmente excluida, y donde se ubica el 39.3\% de ciudadanos y ciudadanas considerados en el escalafón económico y social más pobre. ${ }^{1}$ Esta grave situación supone un desafío permanente para quienes elaboran políticas públicas en el ámbito jurisdiccional.

Para abordar el desafío en mención, sostenemos que es fundamental introducir en el debate la discusión acerca de la noción de acceso a la justicia y de cómo desde ella se puede reflexionar sobre la necesidad de ampliar su contenido, de modo que se incluya una serie de prácticas y mecanismos que tradicionalmente han permanecido al margen, pero que permitirían, de ser incorporados, satisfacer el derecho a la justicia.

No se trata en el presente trabajo de discutir sobre si la noción de acceso a la justicia tiene o no recepción normativa, ya que diversos instrumentos internacionales que el Perú ha ratificado así lo reconocen y varias normas internas también lo refieren. ${ }^{2}$ El asunto a tratar radica en si, en condiciones de desigualdad real, el ciudadano común y corriente tiene la posibilidad de acceder a alguno de los mecanismos existentes, que le permitan legítimamente determinar derechos y resolver su conflicto, con resultados que tengan validez ante terceros. Ello debiera significar que no solamente importen las vías judiciales, sino aquellas otras formas que la Constitución Política, los tratados internacionales y la legislación ordinaria reconocen.

* ProfesorordinariodelDepartamentoAcadémicode Derechodela PontificiaUniversidadCatólicadel Perú.

1 Según datos del Instituto Nacional de Estadística e Informática (INEI) de 2007. La pobreza en el Perú en el año 2007. Informe técnico. Lima: INEI, 2007.

2 La Declaración Universal de los Derechos Humanos (artículo 10); la Declaración Americana de Derechos y Deberes del Hombre (artículo XVIII); el Pacto Internacional de Derechos Civiles y Políticos (artículo 14, inciso 1); la Convención Americana de Derechos Humanos (artículo 8, inciso 1; artículo 25); la Convención InternacionalsobreEliminacióndeTodaslasFormasdeDiscriminaciónRacial(artículos5y6);laConstitución Política del Perú (artículo 2, inciso 2, y artículo 139, inciso 3). 
Esta discusión no resulta banal ni carece de trascendencia, ya que, dependiendo de la posición que se asuma, se adoptarán o se dejarán de adoptar determinadas medidas por parte de los funcionarios estatales. De este modo, si se asume una concepción «tradicional», es decir, que por acceso a la justicia solamente deba entenderse la creación de condiciones para acceder a los tribunales estatales, solo bastará concentrarse en promover la creación de más juzgados y fiscalías en el país y, en general, instancias estatales que coadyuven a la mejor impartición de justicia. Sin embargo, si se asume una concepción «integral», es decir, que por acceso a la justicia no solamente deba comprenderse la ampliación de la oferta estatal de justicia, sino que además implique el reconocimiento de toda clase de mecanismos válidos que resuelvan conflictos de modo pacífico, entonces deberán establecerse las políticas públicas necesarias para reconocer y promocionar desde las formas de justicia comunal o indígenas tan arraigadas en nuestro país, hasta los medios alternativos de resolución de conflictos, de más reciente incorporación legislativa.

Estamos, entonces, ante un debate relevante que, una vez establecidas las posiciones en uno u otro sentido, debería significar que se desarrollen acciones concretas que beneficien a la población para la que este derecho es restringido. En tal sentido, en las líneas siguientes profundizaremos en la pertinencia de replantear la noción de acceso a la justicia y la necesidad de identificar las barreras u obstáculos existentes en el país, y finalmente haremos una mención acerca de lo que se ha establecido en los últimos diagnósticos serios de reforma judicial y la conveniencia de coordinar una agenda común para promover la concreción del derecho al acceso a la justicia.

\section{HACIA UNA (NUEVA) NOCIÓN DE ACCESO A LA JUSTICIA}

Referirse a qué entendemos por este concepto requiere de una revisión exhaustiva de cómo ha evolucionado en el tiempo. Inicialmente y desde un enfoque general, aludir al derecho al acceso a la justicia significaba que los ciudadanos puedan hacer valer sus derechos y/o resolver sus disputas bajo el auspicio del Estado. ${ }^{3}$ Sin embargo, esta noción ha transitado sucesivas etapas que van desde el establecimiento de una asociación directa con garantías procesales básicas (tutela judicial), de acuerdo con las cuales resultaba suficiente proveerle al ciudadano de más tribunales de justicia y de mejor calidad, con lo que se satisfaría esta noción, hasta una visión vinculada a un derecho más complejo, referido a toda clase de mecanismo eficaz que permita solucionar un conflicto de relevancia jurídica. 
Tal recorrido no ha sido fácil y es aceptado solo parcialmente por los diversos operadores de justicia. Esto no obedece solo al desconocimiento del tema, sino también y sobre todo a la ideología que estaría detrás de estas concepciones, ${ }^{4}$ que en un caso permitirían mantener el actual sistema de impartición de justicia, con sus aciertos u omisiones, y, en otro, plantear un enfoque radicalmente distinto que afirme la transformación del sistema de justicia hacia uno inclusivo y pluralista. No estamos, por lo tanto, ante diferencias de matiz, ya que la opción por una u otra visión de lo que se entiende por acceso la justicia conllevaría un desarrollo de acciones de política pública con enfoques distintos. ${ }^{5}$

Pocas investigaciones se han ocupado de este asunto. Es casi obligatorio referirse al proyecto de Florencia para el acceso a la justicia que Mauro Cappelletti dirigió en la pasada década de 1970, en el que se pasa revista de los diversos esfuerzos llevados a cabo por varios países para contrarrestar las diversas barreras de acceso, asociadas básicamente con la noción de pobreza legal ${ }^{6}$ y con la ausencia del Estado, sea porque no se le dotaba de los recursos suficientes para contar con el número necesario de abogados de oficio o porque la población desconocía sus derechos.

Más tarde, en el continente latinoamericano, algunas organizaciones internacionales se empezaron a plantear el tema por su evidente conexión con el desarrollo de los derechos humanos y la búsqueda de justicia social, tomando en cuenta, especialmente las particularidades de la realidad diversa y heterogénea de nuestros países. Este ha sido el caso del Banco Interamericano de Desarrollo (BID) que, en asociación con el Instituto Interamericano de Derechos Humanos, realizó en 1999 una investigación, en siete países de la región, sobre el fortalecimiento del acceso a la justicia, con la idea de influir en otros organismos de cooperación, para que incorporasen dentro de sus líneas de acción la noción de acceso desde un enfoque más equitativo, para atender a los grupos desprotegidos, y desde una perspectiva de desarrollo, es decir, que se asuma como presupuesto necesario en la elaboración de políticas públicas sobre reforma de la justicia, a partir del entendimiento de que se trata de un derecho fundamental que no puede ser dejado de lado.?

4 Talvezestaideologíapresentepodríacatalogarsedemaneraapropiadacomolaculturajurídicaqueprevalece mayoritariamenteen losabogadosquese desempeñan comojueces, litigantes, profesores oacadémicos, yqueestáreferidaalasopiniones, creencias, rutinas, hábitos detrabajo, ideas y valoraciones presentesen sus actividades. Tomado de BINDER, Alberto. «Lacultura jurídica, entre latradicióny la innovación». En Luis Pásara(editor). Los actores de lajusticia latinoamericana. Salamanca: Ediciones Universidad de Salamanca, 2007, p. 27.

5 Un buen ejemplo de cómo estas concepciones se traducen en la definición de políticas públicas es el presupuesto del Poder Judicial de los últimos años. La poca mención que se hace al tema de acceso a la justiciaestáreferidaúnicamentealacreación dejuzgadosysalasespecializadas, asícomoalequipamiento delos despachos jurisdiccionales. Se descartacualquier clase de apoyoa sectores que noforman partede la carrera judicial, como la Justicia de Paz.

6 Lapobrezalegal puedeserdefinidacomolaincapacidaddeunapersonaparautilizarlasnormas, instituciones delEstadoyotrosmecanismosalternativoscomomedioidóneoparaejercerderechosysolucionarconflictos. Véase DEL MASTRo, Fernando. «Pobreza legal y pobreza legal extrema: ¿quiénes son los responsables?». Thēmis Revista de Derecho, no 53, 2007, Lima, p. 260.

7 Thompson, José (coordinador). Acceso a la justicia y equidad: estudio en siete países de América Latina. San José: Banco Interamericano de Desarrollo e Instituto Interamericano de Derechos Humanos, 2000.

EL ACCESO A LA JUSTICIA COMO CONDICIÓN PARA UNA REFORMA JUDICIAL EN SERIO 
Estos novedosos enfoques han ido madurando, gracias a recientes investigaciones y porque la realidad obligaba a considerar que, por más esfuerzos de reforma de la justicia que se hiciesen, si no se tomaba en cuenta a la mayoría de la población que no accedía a los tribunales jurisdiccionales, no se alcanzaría la meta de satisfacer el derecho al acceso efectivo a la justicia. ${ }^{8}$ Así, pues, se ha ido produciendo una paulatina mutación del derecho fundamental a acceder a la justicia como un derecho «para todos» hacia un derecho «para quienes carecen de medios» por su posición económica, racial, de género, cultural, etcétera.

\section{1. ¿Qué es entonces acceso a la justicia?}

A partir de la evolución que ha ido sufriendo este concepto, hoy se lo puede definir como el derecho de las personas, sin distinción de sexo, raza, edad, identidad sexual, ideología política o creencias religiosas, a obtener una respuesta satisfactoria ante sus necesidades jurídicas. ${ }^{9}$ De esta definición, se colige que acceso efectivo a la justicia no es equivalente a tutela judicial del Estado, ya que tal aproximación reduce este derecho fundamental a brindar garantías judiciales antes y durante un proceso judicial, cuando en la inmensa mayoría de casos la población ni siquiera puede acceder a un tribunal.

Tampoco creemos que la noción planteada pueda asociarse solamente con mejorar la cobertura estatal. Al respecto, es pertinente referirse a las distintas concepciones que reposan detrás de esta idea. Por un lado, tenemos un enfoque institucionalista que "se centra en la maquinaria del ámbito público de la administración de justicia». ${ }^{10}$ Para esta corriente, el problema de necesidades jurídicas se podrá abordar con más tribunales, mejores equipamientos y más recursos humanos, lo que permitirá ampliar la atención del Estado.

Por otro lado, está el enfoque integral de acceso a la justicia, promovido inicialmente desde el Programa de Naciones Unidas para el Desarrollo (PNUD), pero asumido posteriormente por diversas organizaciones de la sociedad civil que velan por la reforma de la justicia, especialmente en Latinoamérica. Esta visión entiende el acceso a la justicia «como un instrumento para la transformación de las relaciones de poder que perpetúan la exclusión, la pobreza y la subordinación de grupos tales como mujeres, presos, indígenas, migrantes, discapacitados, niños, ancianos, población de bajos ingresos, etc.». ${ }^{11}$

8 Destaca un reciente informe a nivel latinoamericano: Lovatón PALACIOs, David. «Acceso a la justicia. Llave para la gobernabilidad". En Informe Final del proyecto Lineamientos y Buenas Prácticas para un Adecuado Acceso a la Justicia en las Américas. Lima: Organización de Estados Americanos y Consorcio Justicia Viva, 2007.

9 Programa de las Naciones Unidas para el Desarrollo. Manual de políticas públicas para el acceso a la justicia. Buenos Aires: Ediciones del Instituto, 2005, p. 7. 
En nuestra opinión, este es el enfoque más apropiado para la realidad de nuestros países, ya que supone el punto de partida más completo para describir los serios problemas que se presentan cuando no se satisfacen las necesidades jurídicas de la población tradicionalmente excluida ni la forma como podrían ser mejor abordadas. Asimismo, desde esta concepción es entendible que se asuma que el acceso a la justicia es ante todo un derecho por el que el ciudadano, en tanto titular de tal derecho, puede exigirle al Estado su cumplimiento o las medidas para que sean efectivos. Así se descartan aquellas nociones que entienden a la justicia solo como un servicio en el que el litigante es un usuario (cliente), que puede, eventualmente, ver cómo aquel queda restringido, es afectado por sus altos costos o incluso resulta privatizado. ${ }^{12}$

De manera complementaria, cabe plantear que cualquier diseño y ejecución de políticas públicas que se quiera implementar en nuestra realidad tendrá que descartar como línea de inicio aquella visión que concibe que la reforma de la justicia es equivalente a la mejora de su acceso. Por el contrario, desde este nuevo enfoque, lo pertinente sería referirse a la transformación del sistema de justicia, entendiendo por ello la modificación de:

[...] los mecanismos perpetuadores [sic] de la desigualdad a instancias de participación y empoderamiento [...] lo cual pasará por la adopción de una estrategia en materia de justicia asentada en: 1) ampliación de la cobertura estatal; 2) incorporación al sistema de justicia de los mecanismos tradicionales y comunitarios de resolución de conflictos; 3) focalización de las políticas públicas en los grupos más vulnerables y desprotegidos de la sociedad. ${ }^{13}$

Por tanto, dependiendo de cómo plantean sus estrategias los diseñadores de políticas públicas en materia de justicia, podremos descifrar si los esfuerzos se están encaminando realmente hacia la superación de las barreras de acceso a la justicia o si solo están promoviendo mejoras cuantitativas o cualitativas de los recursos judiciales, sin alterar la asimetría de partida de los ciudadanos para ingresar a un sistema de resolución de conflictos.

Del mismo modo, a nivel jurisprudencial, dependiendo de cómo se interpreta el derecho de acceso a la justicia frente a la tutela jurisdiccional, apreciaremos la mirada que nuestros jueces brindan a uno u otro enfoque. Si se insiste en sostener que el derecho a la tutela jurisdiccional tiene entre sus atributos el acceso a la justicia, ${ }^{14}$ entendido solo como el derecho de cualquier persona a promover la actividad jurisdiccional del

12 Francia, Luis. «El auxilio judicial en el marco del debido proceso». En Acceso a la justicia y Defensoría del Pueblo. Lima: Comisión Andina de Juristas, 2001, p. 228.

13 Ibid., p. 12.

14 Sentencia del 5 de enero de 2006, fundamentos 15 y 16, expediente 0015-2005-PI/TC, del Tribunal Constitucional, que mantiene una línea jurisprudencial expresada en la STC 010-2001-AI/TC (fundamento 10), en la STC 763-2005-PA (fundamento 6), entre otras. 
Estado sin que se le obstruya, impida o disuada irrazonablemente, así como el derecho a la efectividad de las resoluciones judiciales; o si se prefiere replantear este razonamiento para coordinar una lectura conjunta del derecho a la justicia con el principio de igualdad, de manera que el derecho al acceso sea el género y el derecho a la tutela la especie.

Después de estas precisiones, más que insistir en la creación de nuevas unidades jurisdiccionales, pensando erróneamente que de este modo se promueve una mayor atención a los justiciables, debería reflexionarse acerca de qué se está haciendo para incluir (reconocer) mecanismos comunitarios de resolución de conflictos, como la justicia de paz y la justicia indígena, y cómo se piensa diagnosticar las necesidades jurídicas de los grupos más desprotegidos de la población, de manera que allí puedan dirigirse los recursos materiales y humanos que el Estado tiene la obligación de proveer

\section{II.BARRERAS DE ACCESO A LA JUSTICIA: ¿DE QUÉ ESTAMOS HABLANDO?}

Uno de los aspectos clave para afrontar la falta de acceso a la justicia está referido a la «invisibilización» de aquellos obstáculos que hacen imposible acceder a instancias en las que los ciudadanos puedan hacer valer sus derechos y/o resolver sus conflictos de manera real. ${ }^{15}$ Es una situación especialmente relevante en sociedades como la nuestra, que atraviesan por diferencias que conducen a que ciertos grupos de personas - no precisamente minoritarios - atraviesen de facto situaciones de discriminación debido a su condición socioeconómica, física, de género, racial, cultural, etcétera.

Después de todo, el derecho de acceder a la justicia tiene que ser garantizado para que su ejercicio pueda serlo en condiciones de igualdad, de allí que exista la obligación estatal de remover todos los obstáculos que impiden su ejercicio, como en reiteradas ocasiones lo ha establecido la jurisprudencia de la Corte Interamericana de Derechos Humanos. ${ }^{16}$

En este sentido, los obstáculos o barreras que impiden el acceso a la justicia pueden ser agrupados en tres clases: las barreras institucionales que afectan a toda la población, indistintamente de su posición social o económica; las barreras económicas que afectan las transacciones y el desarrollo de un país, así como a sectores poblacionales precarios; y las

15 Roche, Carmen Luisa y Jacqueline Richter. «Barreras para el acceso a la justicia». En AA.VV. Derechos humanos, equidad y acceso a la justicia. Caracas: Instituto Latinoamericano de Investigaciones Sociales, 2005.

16 La Corte IDH ha sostenido que "esta disposición de la Convención [refiriéndose al artículo 8.1] consagra el derecho de acceso a la justicia. De ella se desprende que los Estados no deben interponer trabas a las personas que acudan a los jueces o tribunales en busca de que sus derechos sean determinados o protegidos. Cualquier norma o medida de orden interno que imponga costos o dificulte de cualquier otra maneraelaccesodelosindividuosalostribunales,yquenoestéjustificadaporlasrazonablesnecesidades delapropiaadministracióndejusticia, debeentendersecontrariaalprecitadoartículo8.1 delaConvención»" (la cursiva es nuestra). Caso Cantos, Sentencia de la Corte IDH del 28 de septiembre de 2002. 
barreras sociales que afectan a determinados grupos sociales, especialmente a los tradicionalmente marginados. ${ }^{17}$

\section{Barreras institucionales}

Son aquellos obstáculos que involucran a sectores significativos no mayoritarios de la población. Se refieren a las barreras que el propio sistema de justicia origina por su concepción o diseño, y que conducen a que los ciudadanos no recurran a aquel..$^{18}$ Entre ellos tenemos:

\subsection{Educación jurídica}

Se refiere a cómo se concibe la educación de los profesionales del Derecho: sumamente formalista, neutra y bastante distante de la realidad y de los conflictos más recurrentes de la población. Esto se evidenciará de modo grave cuando la brecha entre el discurso jurídico y lo cotidiano alcance niveles más altos, lo que conduciría, con cierta frecuencia, a prescindir de los modos de solución de conflictos tradicionales basados en una ley extraña o desfasada de la sociedad. Al respecto, se trataría de «un modelo de enseñanza que busca reproducir un cierto orden preconstituido por los códigos y leyes y que, por ello, descalifica la critica externa $[\ldots] »{ }^{19}$

\subsection{Carga procesal}

Se refiere a la voluminosa congestión de los despachos judiciales con una serie de expedientes pendientes por resolver, que hacen que los procesos tarden demasiado. Se atribuye con cierta ligereza a cierta «litigiosidad» de la población que ingresaría excesivas causas, cuando recientes estudios señalan que tendría más bien que ver con la baja productividad del Poder Judicial. ${ }^{20}$

\subsection{Organización del Poder Judicial y de otras instituciones de justicia}

Se refiere a la poca adaptabilidad y disposición a modernizar la administración de los despachos judiciales, distantes geográficamente de las principales necesidades jurídicas de la población. Este problema comprende a otras instituciones vinculadas, tales como el Ministerio

17 BHANSALI, Lisa. «Perú-La oportunidad de un país diferente: próspero, equitativoy gobernable». En Informe del Banco Mundial. Lima: Banco Mundial, 2006, p. 793. Natalia Gherardi cita otra clasificación de estos obstáculos; los clasifica en operativos - cuando dificultan la efectividad y eficiencia de la justicia- 0 estructurales-cuandoestánrelacionadosconaspectosquehacenalapropiaorganizacióndelasociedad-. Véase «Accesoalajusticiayserviciosjurídicosgratuitosenexperienciascomparadas».EnHaydéeBıRGıNy Beatriz Konen. Acceso a la justicia como garantía de igualdad. Buenos Aires: Editorial Biblos, 2006, p. 134.

18 Ennuestropaís, es frecuentepercibirun desfaseentre unaserie de instituciones jurídicas importadas y las prácticas frecuentes de la población.

19 Gonzales Mantilla, Gorki. «Enseñanza del Derecho, cultura legal y reforma judicial». En La enseñanza del Derecho o los molinos de viento cambios, resistencias y continuidades. Lima: Palestra Editores, 2008, p. 102.

20 Al respecto puede revisarse una interesante investigación de Hernández Breña, Wilson. Carga y descarga procesal en el Poder Judicial, 1996-2005. De lo general a lo particular, de lo cotidiano a lo preocupante. Lima: Consorcio Justicia Viva, 2006.

EL ACCESO A LA JUSTICIA COMO CONDICIÓN PARA UNA REFORMA JUDICIALEN SERIO 
Público, el Ministerio de Justicia, el Consejo Nacional de la Magistratura y la Academia de la Magistratura.

\subsection{Presupuesto del Poder Judicial y de otras instituciones de justicia}

Se refiere a la poca disposición de los poderes públicos para atender las demandas de más recursos y a la manera en que estos son asignados: priorizan gastos fijos, mas no la ampliación de la oferta estatal de justicia. ${ }^{21} \mathrm{Al}$ respecto, si se revisa la estructura presupuestal del Poder Judicial en los acápites referidos al acceso a la justicia, se establecen medidas para conformar nuevos despachos judiciales, mejorar la infraestructura o modernizar los equipos informáticos. ${ }^{22}$

\section{Barreras sociales}

Afectan a determinados grupos sociales por su situación de desigualdad real o vulnerabilidad, lo cual se evidenciará al pretender acceder a alguna instancia de impartición de justicia. Entre ellas tenemos:

\subsection{Barreras lingüísticas}

A pesar de que en el Perú existen varios millones de personas que hablan idiomas distintos del castellano, es casi remota la posibilidad de expresarse en su lengua materna durante un proceso judicial, por la ausencia de intérpretes, aun cuando se trata de una garantía del debido proceso. De este modo, se aprecia la inexistencia de políticas estatales que promuevan la incorporación de funcionarios judiciales bilingües o de un sistema oficial de traductores judiciales. Al respecto, el Poder Judicial no cuenta con un registro de los distritos judiciales donde se requieren operadores de justicia que manejen idiomas nativos e indígenas. Tampoco el Consejo Nacional de la Magistratura designa jueces y fiscales con conocimiento del idioma quechua o aymara para las zonas del país donde están asentadas las comunidades campesinas o nativas. ${ }^{23}$

\subsection{Barreras culturales}

Si bien no existen estadísticas determinantes, dependiendo de alguna variable, entre $25 \%$ y $48 \%$ de los hogares en el país se autodenominan indígenas. ${ }^{24} \mathrm{~A}$ partir de ello, adquiere total relevancia la discusión sobre cómo está diseñado el actual sistema estatal de justicia, sobre su pertinencia y la cultura jurídica predominante, que no responden

21 En los últimos siete años, el presupuesto del Poder Judicial se ha incrementado paulatinamente y no necesariamente se ha apreciado una mejora del servicio judicial. Al respecto puede revisarse HERNÁNDEZ BreÑa, Wilson. Op. cit.

22 lbid., p. 48.

23 Al respecto puede revisarse el documento Barreras para el acceso a la justicia en América Latina, elaborado por el Instituto de Defensa Legal, la Fundación para el Debido Proceso Legal y otros, presentado ante la Comisión Interamericana de Derechos Humanos en su período de sesiones de octubre de 2008. En <http:// www.justiciaviva.org.pe/nuevos/2008/octubre/30/informe_acceso.pdf>, p. 13.

24 En el censo de 2001, se diferenciaba entre un total de cinco indicadores: lengua materna indígena; autoidentificacióncomoindígena;ambasopcionesjuntas;usodelidiomaindígenaenlavidadiaria;ypadres, abuelos o pareja con idioma materno indígena. Tomado de MeEntzen, Ángela. Políticas públicas para los pueblos indígenas en América Latina. Lima: Fundación Konrad Adenauer, 2007, p. 16. 
necesariamente a las demandas jurídicas de la población no urbana u occidental. En tal sentido, es conveniente la discusión acerca de lo que entendemos por diversidad cultural y de cómo ello afecta la práctica jurídica vigente al resolver conflictos.

Ello porque esta realidad debiera generar en nuestro país el replanteamiento de la noción de que existe un solo sistema jurídico para atender esta diversidad, cuando lo pertinente es que, al existir diversos espacios regulatorios, en este caso de comunidades campesinas y nativas, debiera reconocerse esta situación y crear las condiciones para una óptima coordinación con el sistema estatal, de forma que sea la población aquella favorecida con este intercambio.

Se reafirma este punto de vista cuando la propia normativa constitucional e internacional establece que nuestro país se ratifica como respetuoso del derecho a la identidad cultural y, concretamente, reconoce el pluralismo jurídico establecido en la Constitución Política (artículo 149), que implica el respeto de las formas de resolución de conflictos impartidas desde las comunidades campesinas y nativas, así como desde las rondas campesinas.

Sin embargo, este reconocimiento no ha sido suficiente para que los operadores estatales de justicia apliquen dicha normativa. Ello ha generado diversos callejones sin salida, porque al intentar aplicar el artículo constitucional 149 se ha reparado en la ausencia de una norma de desarrollo legislativo que determine el reparto de competencias entre ambos sistemas jurídicos.

Al respecto, si bien es cierto el citado artículo 149 establece la necesidad de una ley de desarrollo, ello no significa que se encuentre en suspenso el reconocimiento de la potestad jurisdiccional de las comunidades campesinas, nativas y de las rondas, ya que, de la lectura de dicho texto, se desprende este reconocimiento. En este sentido, el debate radica en cómo esta ideología jurídica legalista tolera que la norma constitucional prevalezca y que se plasme en el accionar de los operadores.

\subsection{Barreras de género}

Para efectos del presente trabajo, consideramos que género es una categoría que alude a las construcciones sociales y culturales sobre la base de las diferencias sexuales, ${ }^{25}$ lo que, desde el punto de vista del derecho, ha tenido escasa relevancia para intentar explicar las desigualdades entre hombres y mujeres. Sobre esta línea, dichos patrones sociales construidos tienen un impacto significativo al buscar satisfacer necesidades jurídicas concretas, como por ejemplo el caso de una mujer víctima de violencia familiar que, por los estereotipos existentes, es incapaz de denunciar a un varón agresor. En el ámbito rural, esta situación se agrava y 
constituye un serio obstáculo para que las mujeres puedan hacer respetar su calidad de ciudadanas. Aquí, se observa una clara predominancia de varones que imparten justicia de acuerdo con su perspectiva. ${ }^{26}$

Por ello, el enfoque de género es pertinente como un método de análisis que permita diferenciar las necesidades propias de las mujeres que, en el caso del acceso a la justicia, pasen por estrategias o políticas que tengan en cuenta el impacto diferenciado entre hombres y mujeres. ${ }^{27} \mathrm{Al}$ respecto, dos ideas complementarias resultan pertinentes para comprender esta reflexión. Por un lado, una reciente investigación ${ }^{28}$ que da cuenta sobre cómo, en el Poder Judicial, no existe paridad entre la cantidad de magistrados varones y mujeres, lo cual podría evitar la discriminación. Ello mostraría la urgencia de promover cuotas de género también dentro de este ámbito. De otro lado, llama la atención la cada vez mayor preocupación por este tema incluso a nivel internacional, como lo resalta un informe de la Comisión Interamericana de Derechos Humanos, que se ha ocupado de este tema y ha señalado recomendaciones a los países miembros sobre las medidas que deberían promoverse para mejorar el acceso a la justicia. ${ }^{29}$

\section{Barreras económicas}

Aquí nos referimos básicamente a cómo la pobreza impacta en la concreción del derecho a la justicia. Al respecto, diversos enfoques han centrado la magnitud de este problema en relación con la insatisfacción de una serie de derechos económicos y sociales, de allí que en tiempos recientes se vincule la noción de pobreza con ciudadanía, la cual se vería también afectada cuando no se concreta el cumplimiento de una serie de derechos que incluyen los de acceder a alguna de las formas legitimadas de resolución de conflictos reconocidas en el país.

Asimismo, frente a la constatación de que alrededor del $40 \%$ de la población se encuentra en cierto nivel de pobreza, los costos económicos de acceder a alguna forma de resolución de conflictos representan una traba para un buen porcentaje de ciudadanos en el país. Aquí pueden identificarse como principales barreras los costos que deben asumirse para litigar, ya sea por aranceles judiciales o por honorarios de abogados.

Sobre lo primero, los costos formales de un proceso judicial resultan una forma indirecta de discriminación para personas de menores recursos. $\mathrm{Si}$

26 Al respecto puede revisarse MEentzen, Ángela. Relaciones de género, poder eidentidad femenina en cambio. El orden social de los aymaras rurales peruanos desde la perspectiva femenina. Cusco: Centro de Estudios Regionales Andinos Bartolomé de las Casas, 2007.

27 FAcio, Aldo. "Con los lentes del género se ve otro Derecho». En Reducción de la pobreza, gobernabilidad democrática y equidad de género. Proyectos de Promoción de Políticas de Género/GTZ, tomo II. Managua: GTZ (Cooperación Técnica Alemana), 2003, p. 145.

28 Demus. Para una justicia diferente. Temas para la reforma judicial desde y para las mujeres. Lima: DEMUS, 2007.

29 Organización de los Estados Americanos. Comisión Interamericana de Derechos Humanos. Acceso a la justicia para las mujeres víctimas de violencia en las Américas. Washington: Secretaría General de la OEA, 2007, p. 122. 
a ello agregamos las serias dificultades que existen desde el Estado para proveer de defensa letrada gratuita a quienes no pueden asumirla, tendremos un panorama de evidente indefensión para un segmento social específico. Al respecto, según cifras del Ministerio de Justicia, existen alrededor de setecientos abogados de oficio que ejercen esta labor en todo el país, cifra claramente insuficiente si se considera la demanda por este servicio.

Sobre los pagos por tasas judiciales, debería reevaluarse la posibilidad de establecer la exoneración del pago por este requisito a los pobladores de aquellos distritos identificados por debajo de la línea de pobreza, ${ }^{30}$ así como difundir y flexibilizar en los demás lugares la posibilidad de acogerse al auxilio judicial. ${ }^{31}$

Otro obstáculo tiene que ver con los costos informales y se refiere a la corrupción existente en las instancias estatales de justicia que desalientan a que el ciudadano acuda a ellas para dirimir sus controversias. No es casualidad que el informe de Transparencia Internacional de 2007, dedicado a los sistemas judiciales, señale a este mal endémico como una de las principales barreras de acceso a la justicia, ${ }^{32}$ al indicar que el Perú se ubica en los primeros niveles de corrupción.

\section{HACIA UN SISTEMA DE JUSTICIA INCLUSIVO}

Los últimos documentos de trascendencia nacional que se han referido a la reforma del sistema de justicia han sido los informes finales de la Comisión Especial de Reforma Integral de la Administración de Justicia (CERIAJUS) y el Acuerdo Nacional, ambos entre 2003 y 2004. En el primer caso, el capítulo inicial de dicho informe señaló que el propósito reformador que orientaba aquel trabajo tenía como objetivo la búsqueda de un sistema de justicia inclusivo, que eliminase las desigualdades existentes en el país; de allí que, entre otros temas, incorporara de modo explícito la jurisdicción comunal, así como una serie de recomendaciones para que su reconocimiento no quedase en fórmulas declarativas. ${ }^{33}$

30 Actualmente,existen 531 distritos beneficiadosconlaexoneración delastasasjudiciales, locual beneficia aproximadamente a cerca de tres millones de personas. Sería conveniente verificar cuántos distritos más deben alcanzar este beneficio.

31 Elotorgamientodelauxiliojudicialhasidoreguladoporresoluciónadministrativa182-2004-CE-PJ,mediante lacual seapruebael «Procedimientoparala concesión delbeneficiodelauxiliojudicial», queestablece una serie de requisitos que no corresponden a la realidad de pobreza en la que se encuentran los ciudadanos solicitantes. Eselcasodequienesrequierenestebeneficioylessolicitanacreditarsussituacióndepobreza con documentos como recibo de electricidad, agua, teléfono o cable, etcétera, que no son los medios más apropiados para acreditar que una persona carece de recursos económicos.

32 Transparencia Internacional. Informe global de la corrupción 2007: corrupción en el sistema judicial. Cambridge: Cambridge University Press, 2007, p. 22. También se puede obtener en la siguiente dirección electrónica: <http://www.justiciaviva.org.pe/nuevos/2007/mayo/31/informe global ingles.pdf>.

33 EI Grupo de Trabajo de Acceso a la Justicia estableció que: «El principal problema de la justicia en el Perú sonsus serias limitacionesalaccesouniversaldelos ciudadanosalajusticia».Véase ComISIÓNESPECIALPARA la Reforma Integral de la Administración de Justicia. Plan Nacional para la Reforma de la Administración de Justicia. Impreso en Lima, 23 de abril de 2004, p. 83. También se puede obtener en la siguiente dirección electrónica: <http://www.mpfn.gob.pe/descargas/ceriajus/gtt2.pdf>.

EL ACCESO A LA JUSTICIA COMO CONDICIÓN PARA UNA REFORMA JUDICIAL EN SERIO 
Respecto del Acuerdo Nacional, la política 28 se denominaba «Vigencia plena de la Constitución y los derechos humanos, acceso a la justicia e independencia de la judicatura», y establecía el compromiso de garantizar el acceso universal a la justicia, promover la justicia de paz y la autonomía, independencia y el presupuesto del Poder Judicial, así como regular la complementariedad entre este y la justicia comunal.

De tal modo, en ambos textos se admitía una realidad innegable: la existencia en nuestro medio de una pluralidad de sistemas jurídicos sustentados en diversas tradiciones culturales de comunidades campesinas y amazónicas, respectivamente, que debían ser incorporados al discurso oficial, mediante políticas concretas para favorecer estas prácticas, entre los cuales se encuentra la facultad de impartir justicia. Se buscaba ampararlas, así, en coherencia con lo postulado en el artículo 2, inciso 19, de la Constitución Política, que reconoce el derecho a la identidad étnica y cultural.

Muy a nuestro pesar, tenemos que afirmar que esta clara opción no ha tenido en las gestiones públicas sucesivas el empuje necesario para traducirlas en medidas concretas, que promoviesen este nuevo enfoque del acceso a la justicia que permitiera una diferente agenda de temas que transformara el actual sistema hacia uno más democrático e incluyente. Esto puede explicar por qué existe una brecha cada vez más ancha entre el funcionamiento de las instituciones vinculadas con la justicia y la percepción ciudadana al respecto. ${ }^{34}$

Extraña mucho esta desidia estatal para asumir políticas públicas que favorezcan medidas específicas en favor de los grupos vulnerables, que tengan una consistencia en el tiempo y que sean coherentes. Por ello proponemos algunas ideas, sin pretender cerrar la discusión, de lo que por lo menos debiera efectivizarse:

1. Establecer, como punto de consenso para llevar a cabo una reforma de la administración de justicia, una visión integral que comience por reconocer que el acceso a la justicia es el campo de partida para los demás temas.

2. Reconocer una noción de acceso a la justicia en el sentido más amplio posible (enfoque integral), que requiere la participación de diversas instancias estatales vinculadas con la administración de justicia. No es un tema que solo ataña al Poder Judicial o al Ministerio de Justicia.

3. Es fundamental la participación ciudadana en la identificación de sus necesidades jurídicas, por lo que los poderes públicos

34 Alrespecto,resultansumamentegráficoslosresultadosdelBarómetroSocial Noviembre2008:IIIEncuesta Anual sobre Administración de Justicia, que publicala Universidad de Lima, y queseñalaque un $11 \%$ de los encuestadosconsiderabacomoprincipalproblemadelajusticialafaltadeacceso, despuésdelacorrupción, que llegaba al $49 \%$. 
debieran esmerarse en indagar primero acerca de ellas para establecer las respuestas idóneas que pueden provenir del Estado o de los particulares.

4. Establecer, como ejes transversales en la adopción de medidas en favor del acceso a la justicia, los enfoques de interculturalidad y género. En el primer caso, dada la heterogeneidad cultural y lingüística del país, es importante efectivizar el pluralismo jurídico que establece la Constitución Política. En el segundo caso, se trata de tomar en consideración, en cada una de las medidas reformadoras, el impacto diferenciado que tienen en varones y mujeres.

A manera de conclusión, podemos sostener que solo en la medida en que se avance en el campo del acceso a la justicia se podrá sostener una reforma de la justicia en el sentido más serio posible, ya que, de imposibilitarse el acceso ciudadano, los demás derechos carecerán de efectividad. Esperemos que no siga demorando esta necesaria coordinación entre las instancias estatales y, especialmente, que, desde el Poder Ejecutivo y el Judicial, se asuma el liderazgo para priorizar acciones en beneficio de la población que lo requiere con más urgencia.

\section{BIBLIOGRAFÍA COMPLEMENTARIA}

BHANSALI, Lisa. «Perú - La oportunidad de un país diferente: próspero, equitativo y gobernable». En Informe del Banco Mundial. Lima: Banco Mundial, 2006.

Comisión Especial para la Reforma Integral de la Administración de JusTICIA. «Plan Nacional para la Reforma de la Administración de Justicia». En $<$ http://www.mpfn.gob.pe/descargas/ceriajus/gtt2.pdf $>$.

De Belaunde, Javier. La reforma del sistema de justicia: ien el camino correcto? Breve balance de su situación actual y los retos pendientes. Lima: Fundación Konrad Adenauer e Instituto Peruano de Economía Social de Mercado, 2006.

FerRandino, Álvaro. «Acceso a la justicia». En Luis Pásara (compilador). En busca de una justicia distinta. Experiencias de reforma en América Latina. Lima: Consorcio Justicia Viva, 2004.

GuevarA GiL, Armando. «Apuntes sobre pluralismo legal». Ius et Veritas, no 19, 1999, Lima.

LA RosA CALLE, Javier. «Acceso a la justicia: elementos para incorporar un enfoque integral de política pública». En Javier La Rosa (editor). Acceso a la Justicia en el mundo rural. Lima: Instituto de Defensa Legal, 2007.

Popkin, Margaret. «Acceso a la justicia, gobernabilidad democrática y sociedad civil». En Carlos Cordovez (editor). Justicia, un vínculo pendiente entre Estado, ciudadanía y desarrollo. Washington: Banco Interamericano de Desarrollo, 2007. 
Roche, Carmen Luisa y Jacqueline RichTER. «Barreras para el acceso a la justicia». En AA.VV. Derechos humanos, equidad y acceso a la justicia. Caracas: Instituto Latinoamericano de Investigaciones Sociales, 2005.

Ruiz MolledA, Juan Carlos. «Justicia comunal y justicia estatal en el Perú: de la confrontación a la coordinación». Derecho Virtual, no 3. <http://www.derechovirtual.com/index.php>. 